\title{
Evaluation of a Multimodal Approach to Postoperative Pain in Patients Undergoing Flank Incision in the Urology Operating Room
}

\author{
Mustafa Nuri Deniz ${ }^{1}$, Arzum Erakgun ${ }^{1}$, Demet Sergin ${ }^{1}$, Elvan Erhan ${ }^{1}$, Mehmet Bülent Semerci ${ }^{2}$, Gülden Uğur ${ }^{1}$ \\ ${ }^{1}$ Department of Anaesthesiology and Reanimation, Faculty of Medicine, Ege University, Izmir, Turkey \\ ${ }^{2}$ Department of Urology, Faculty of Medicine, Ege University, Izmir, Turkey
}

Objective: In this study, we evaluated subcutaneous (sc) morphine in combination with multimodal analgesia for postoperative pain control after radical nephrectomy and pyeloplasty with flank incision.

Methods: Forty-nine patients under The American Society of Anesthesiologists Physical Status classification (ASA) I-III aged 18-85 years undergoing radical nephrectomy and pyeloplasty with flank incision were included in this prospective, randomised study. The patients were divided into two groups (Group O [ $\mathrm{n}=25]$ and Group $M[n=24]$ ) and received standard general anaesthesia. Tramadol $(100 \mathrm{mg})$ and paracetamol $(100 \mathrm{mg})$ were given intravenously before fascia closure and $20 \mathrm{~mL}$ of $0.25 \%$ levobupivacaine was injected locally at surgical incisions in all patients. Patients in Group M also received $0.1 \mathrm{mg} \mathrm{kg}^{-1} \mathrm{morphine}$ subcutaneously. Patient-controlled analgesia (PCA) with tramadol was used for postoperative pain control in both groups. Postoperative pain scores (VAS), vital parameters, side effects, the need for rescue analgesia during 24 hours postoperatively, and patient satisfaction were recorded.

Results: Groups were comparable with respect to demographic data, ASA status, and duration of surgery. There were no significant differences between the groups in postoperative PCA tramadol consumption, rescue analgesia, side effects, or vital parameters. Postoperative pain scores (VAS) in Group M were significantly lower at 30, 45, 60, and 120 minutes compared to Group $\mathrm{O}(\mathrm{p}<0.05)$.

Conclusion: In patients undergoing radical nephrectomy and pyeloplasty with flank incision, subcutaneous morphine in combination with multimodal analgesia decreases early postoperative pain scores compared to multimodal analgesia alone.

Key Words: Subcutaneous, morphine, postoperative pain, flank incision

\section{Introduction}

$\mathrm{A}$ lthough, minimal invasive methods are more popular in the surgical treatment of upper urinary system diseases, open surgery techniques may become necessary in certain conditions. One of these necessities is the radical nephrectomy and pyeloplasty, which are performed by flank incision (1). Incision pain and abdominal asymmetry due to this incision technique enhance postoperative morbidity (2). Various approaches can be performed to prevent pain associated with flank incision. One of these approaches is the multimodal analgesia, which is the administration of various analgesics to provide more effective analgesia (3). Morphine, the oldest opioid, is being used via subcutaneous (sc) route since 1872 (4).

The present study explored the efficacy of multimodal analgesic approach together with sc morphine in controlling incision-associated postoperative pain after radical nephrectomy and pyeloplasty performed by flank incision.

\section{Methods}

After the approval of Ege University Faculty of Medicine, Research Ethics Committee (date: 05.01.2010, no: 09-11.1/32), 49 patients aged between 18 and 85 years and with the American Society of Anesthesiologists Physical Status classification (ASA) I-III who underwent nephrectomy and pyeloplasty via flank incision in the urology surgery room, were included in this prospective randomized study after their consents were obtained. The patients underwent standard monitoring in the surgery room (noninvasive arterial pressure, $\mathrm{ECG}, \mathrm{SpO}_{2}$ ) and vascular access was established by $18 \mathrm{G}$ cannula. The patients were divided into two groups according to a randomization scheme on computer as Group $M(n=25)$ and Group 
$\mathrm{O}(\mathrm{n}=24)$. Anaesthesia induction in the patients that did not undergo premedication was performed with intravenous (iv) $0.5 \mathrm{mg}$ atropine, iv $2 \mathrm{mg} \mathrm{kg}^{-1}$ propofol, iv $1 \mu \mathrm{g} \mathrm{kg}^{-1}$ remifentanil for 30-60 seconds (sec) and iv $0.6 \mathrm{mg} \mathrm{kg}^{-1}$ rocuronium, and maintenance was provided by $\mathrm{O}_{2}$, air, and sevoflurane and iv infusion of $0.25 \mu \mathrm{g} \mathrm{kg}^{-1} \mathrm{~min}^{-1}$ remifentanil. Before the closure of fascia after the procedure, sc $0.1 \mathrm{mg} \mathrm{kg}^{-1}$ morphine was administered through the deltoid muscle in the patients in Group M. No additional procedure was performed in the patients in Group O. Then, during the closure of the fascia at the end of surgery, $100 \mathrm{mg}$ tramadol and $1 \mathrm{~g} / 100 \mathrm{~mL}$ paracetamol was administered in all patients by slow infusion (not shorter than $20 \mathrm{~min}$.). During skin closure, incision line was infiltrated by $20 \mathrm{~mL}$ of $0.25 \%$ levobupivacaine. Decurarization was provided by iv $0.5 \mathrm{mg}$ atropine and iv $1.0 \mathrm{mg}$ neostigmine. Postoperative pain was controlled in all patients by patient-controlled analgesia (PCA) (tramadol PCA; 4 amp tramadol $100 \mathrm{mg} / 100 \mathrm{~mL}$ in $0.9 \% \mathrm{NaCl}$, bolus $20 \mathrm{mg}$, lock time $15 \mathrm{~min}$., 4-hour limit: $200 \mathrm{mg}$ ). In the postoperative period, iv $1 \mathrm{~g} / 100 \mathrm{~mL}$ paracetamol was administered by slow infusion (not shorter than $20 \mathrm{~min}$ ) within the first 24 hours repeating at 6-hour intervals. Scores of visual analogue scale (VAS; $0=$ no pain and $10=$ maximum pain), vital signs, and side events (nausea, vomiting) were recorded for the postoperative 24 hours at minutes $0,15,30$ and 60 and at hours 2, 4, 6, 12 and 24. At the end of the first 24 hours, use of tramadol for PCA and patient satisfaction (very well, good, moderate and poor) were assessed. For severe pain (VAS >4) in the postoperative period, im diclofenac $\mathrm{Na}$ was administered as an additional analgesic. Patients with persistent pain (VAS >4) received iv $50 \mathrm{mg}$ petidine $\mathrm{HCl}$.

\section{Statistical analysis}

For the statistical analysis of data, Chi-Square test was used for gender, ASA, patient satisfaction and adverse events, whereas independent samples test was used to evaluate other variables.

\section{Results}

Demographic characteristics, ASA classification, and duration of surgery were similar in all patients (Table 1). No differences were determined between the groups in terms of

Table 1. Demographic characteristics, ASA and duration of surgery

\begin{tabular}{|lccc|}
\hline Group & Group O & Group M & P value \\
\hline Gender (M/F) & $14 / 11$ & $15 / 9$ & 0.64 \\
\hline ASA (1/2) & $12 / 13$ & $10 / 14$ & 0.65 \\
\hline Age (year) & $58 \pm 11.8$ & $50.7 \pm 15$ & 0.06 \\
\hline Weight $(\mathrm{kg})$ & $74 \pm 14$ & $77 \pm 15$ & 0.47 \\
\hline Height $(\mathrm{cm})$ & $166.5 \pm 8.7$ & $168.6 \pm 9.8$ & 0.42 \\
\hline Duration of surgery (min) & $99.4 \pm 42$ & $129 \pm 41$ & 0.77 \\
\hline ASA: Physical status scoring by American Society of Anaesthesiologists \\
\hline
\end{tabular}

using postoperative tramadol for PCA and need for additional analgesic (diclofenac $\mathrm{Na}$ ) (Table 2). Postoperative pain score was significantly lower at minute 30,45 , and 60 and at hour 2 in the group received postoperative sc morphine as compared to the control group (Figure 1). The groups were similar in terms of adverse event (nausea and vomiting) and patient satisfaction. Pruritus was not observed in any of the patients in the morphine group (Table 2). No significant difference was found between the groups in terms of hemodynamic variables.

\section{Discussion}

Patients have severe postoperative pain after surgical interventions performed by flank incision due to the incision of many muscles (5). Postoperative pain influences patient comfort and satisfaction and prolongs duration of hospital stay and enhances post-procedure complications (6). Postoperative maximum pain is seen within the first 9-12 hours also following general anaesthesia (7). Thus, effective analgesia in the early postoperative period is of great importance in the patients undergoing surgery by flank incision.

Stronger analgesia and lower adverse event with concurrent use of different classes of analgesics with diverse mechanisms of action is an important part of current pain treatment $(5,6,8)$. Thereby, adverse effects of drugs are aimed to minimize by means of using them at appropriate dose due to their contribution of analgesic drugs with different mechanism of action to each other and their synergistic effects (9). Thus, complications are lowered, satisfaction is enhanced, and duration of hospital stay is shortened (10).

Infiltration of wound site with local anaesthetic agents, which is one of the simplest and most effective ways of postoperative pain treatment, may prolong duration of postoperative analgesia $(11,12)$. Besides, the combination of paracetamol and tramadol has been used in many studies due to high analgesic efficacy with low adverse effect and its efficacy has been proven (13-16). Moreover, although sc and iv administration of morphine have similar clinical effect and efficacy $(17,18)$, Stuart-Harris et al. (19) reported that morphine-6-glucuronate (M6G) and morphine-3-glucuronate (M3G), which are active metabolites of morphine, occurred in high amounts after iv administration of morphine. Among these active me-

Table 2. Data of postoperative analgesia, patient satisfaction and adverse event

\begin{tabular}{|lccc|}
\hline Group & Group O & Group M & P value \\
\hline Total tramadol use $(\mathrm{mg})$ & $314.7 \pm 91$ & $295 \pm 116$ & 0.51 \\
\hline $\begin{array}{l}\text { Patient satisfaction } \\
\text { (very well/good/moderate/poor) }\end{array}$ & $3 / 12 / 7 / 3$ & $3 / 19 / 1 / 1$ & 0.7 \\
\hline $\begin{array}{l}\text { Adverse event (nausea and } \\
\text { vomiting-yes/no) }\end{array}$ & $20 / 5$ & $17 / 7$ & 0.45 \\
\hline Need for additional analgesic & 16 & 14 & 0.7 \\
\hline
\end{tabular}




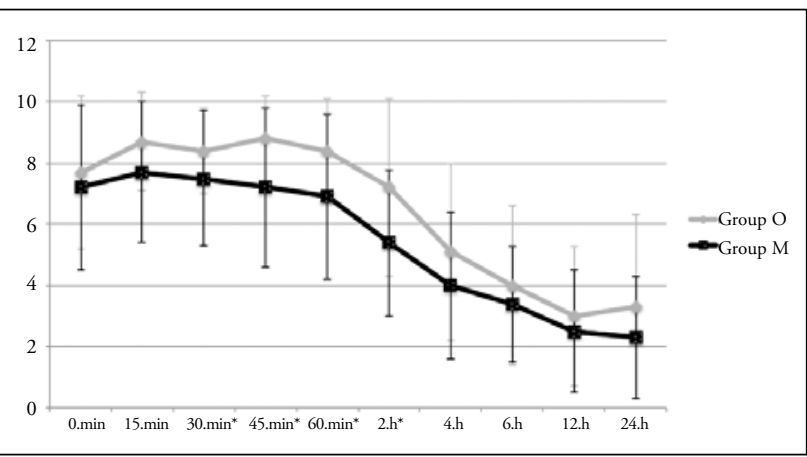

Figure 1. Pain scores according to the postoperative periods ${ }^{*} \mathrm{p}<0.05$ (significant difference between the groups)

tabolites, M3G causes opioid hyperalgesia (20). In the present study, efficacy of sc morphine combined with postoperative PCA and nonopioid local anaesthetic infiltration was investigated in the patients who underwent surgical intervention by flank incision.

Analgesic effect of morphine after administration via sc route begins in 10 minutes (21), plasma concentrations peaks in 15-30 minutes, and can be repeated every 4 hours (22). Aschenbrenner et al. (23) reported its action time as 4-7 hours. Gades et al. (24) conducted a study in mice and stated that sc morphine showed peak analgesic effect within 2-3 hours and that dose interval was 2-3 hours. Semple et al. (25) reported that peak serum morphine concentration was achieved in $16 \pm 7$ minutes after subcutaneous administration. Administration of sc morphine provides earlier postoperative pain control as compared to intramuscular (im) administration; because morphine reaches to peak plasma concentration in 17.5-27.8 minutes after im administration $(26,27)$. Combination of sc morphine with other multimodal analgesia methods has been studied in previous cases who underwent flank incision. In the present study, postoperative VAS scores in the first 24 hours were lower in the group receiving sc morphine during closure of fascia as compared to those in the control group; the difference reached to the level of statistical significance particularly in the early period $\left(30^{\text {th }}, 45^{\text {th }}\right.$ and $60^{\text {th }}$ minutes and $2^{\text {nd }}$ hour).

In the present study, we determined that sc morphine caused a decrease, although not significant, in the need for additional analgesic and in the amount of consumed PCA. Patients rarely encountered nausea and vomiting due to SC morphine administration (28). Choinie et al. (29) found the rate of nausea and vomiting to be $30 \%$ in the group received sc morphine. In the present study, nausea and vomiting was observed by $29 \%$ in the sc morphine group and by $20 \%$ in the control group; no significant difference was determined between the groups. Our results suggested that sc morphine administered at a dose of $0.5 \mathrm{mg} \mathrm{kg}^{-1}$ did not influence the incidence of adverse event as compared to the control group and that $0.5 \mathrm{mg} \mathrm{kg}^{-1}$ was a reliable dose.

\section{Conclusion}

Morphine at a dose of $0.5 \mathrm{mg} \mathrm{kg}^{-1}$ administered via sc route in addition to local anaesthetic infiltration and iv paracetamol and tramadol for postoperative pain control in the patients who underwent nephrectomy and pyeloplasty by flank incision lowered the early postoperative pain scores and it was safe at that dose.

Ethics Committee Approval: Ethics committee approval was received for this study from the ethics committee of Ege University School of Medicine (05.01.2010, 09-11.1/32).

Informed Consent: Written informed consent was obtained from patients who participated in this study.

Peer-review: Externally peer-reviewed.

Author Contributions: Concept - M.N.D., E.E.; Design - M.N.D., E.E., G.U.; Supervision - E.E., G.U., M.B.S.; Funding - M.N.D.; Materials - M.N.D.; Data Collection and/or Processing - M.N.D., E.E., A.E., D.S.; Analysis and/or Interpretation - M.N.D., E.E., A.E., D.S., M.B.S.; Literature Review - M.N.D., E.E., G.U.; Writer - M.N.D., E.E., G.U., A.E., D.S.; Critical Review - M.N.D., E.E.

Conflict of Interest: No conflict of interest was declared by the authors.

Financial Disclosure: The authors declared that this study has received no financial support.

\section{References}

1. Resnick MI. Flank incision. J Urol 2004; 172: 823. [CrossRef]

2. Johnson EM, Remucal MJ, Gillingham KJ, Dahms RA, Najarian JS, Matas AJ. Complications and risks of living donor nephrectomy. Transplantation 1997; 64: 1124-8. [CrossRef]

3. Mugabure Bujedo B, Tranque Bizueta I, González Santos S, Adrián Garde R. [Multimodal approaches to postoperative pain management and convalescence]. Rev Esp Anestesiol Reanim 2007; 54: 29-40.

4. Brenizer AG. Scopolamine-morphine-cocaine anaesthesia in surgery. NJ Med J 1915; 101: 1215-8.

5. Göktaş C, Cangüven Ö, Horuz R, Albayrak S. Dorsal Lumbotomy: A Minimally Invasive Incision. J Kartal TR 2004; 15: 5-7.

6. Bajaj P. Postoperative pain management: organisation and audits. Indian Journal of Anaesthesia 2007; 51: 441-3.

7. Meena N, Cherian MD, Mohan P, Mathews MD, Mathew J, Chandy M. Local wound infiltration with bupivacaine in lumbar laminectomy. Surg Neurol 1997; 47: 120-3. [CrossRef]

8. Rawal N. Postdischarge complications and rehabilitation after ambulatory surgery. Curr Opin Anaesthesiol 2008; 21: 73642. [CrossRef]

9. Hartrick CT. Multimodal postoperative pain management. Am J Healt Syst Pharm 2004; 61: 4-10.

10. Skinner HB. Multimodal acute pain management. Am J Orthop 2004; 33: 5-9.

11. Ersayli DT, Gurbet A, Bekar A, Uckunkaya N, Bilgin H. Effects of perioperatively administered bupivacaine and bupivacaine-methylprednisolone on pain after lumbar discectomy. Spine (Phila Pa 1976) 2006; 31: 2221-6. [CrossRef]

12. Kamaz A, Sögüt Ö, Öksüz H. Comparison Of Wound Infiltration With Bupivacaine And Levobupivacaine For Postoperative 
Analgesia In Patients Operated For Lumbar Disc Herniation. Anatol J Clin Investig 2008; 2: 141-5.

13. Smith AB, Ravikumar TS, Kamin M, Jordan D, Xiang J, Rosenthal $\mathrm{N}$, et al. Combination tramadol plus acetaminophen for postsurgical pain. Am J Surg 2004; 187: 521-7. [CrossRef]

14. Schnitzer T. The new analgesic combination tramadol/acetaminophen. Eur J Anaesthesiol Suppl 2003; 28: 13-7.

15. Bennett RM, Kamin M, Karim R, Rosenthal N. Tramadol and acetaminophen combination tablets in the treatment of fibromyalgia pain: a double-blind, randomized, placebo-controlled study. Am J Med 2003; 114: 537-45. [CrossRef]

16. Edwards JE, McQuay HJ, Moore RA. Combination analgesic efficacy: individual patient data meta-analysis of single-dose oral tramadol plus acetaminophen in acute postoperative pain. J Pain Symptom Manage 2002; 23: 121-30. [CrossRef]

17. Hanks GW, De Conno F, Cherny N, Hanna M, Kalso E, McQuay HJ, et al. Morphine and alternative opioids in cancer pain: the EAPC recommendations. Br J Cancer 2001; 84: 58793. [CrossRef]

18. Elsner F, Radbruch L, Loick G, Gärtner J, Sabatowski R. Intra- venous versus subcutaneous morphine titration in patients with persisting exacerbation of cancer pain. J Palliat Med 2005; 8: 743-50. [CrossRef]

19. Stuart-Harris R, Joel SP, McDonald P, Currow D, Slevin ML. The pharmacokinetics of morphine and morphine glucuronide metabolites after subcutaneous bolus injection and subcutaneous infusion of morphine. Br J Clin Pharmacol 2000; 49: 20714. [CrossRef]

20. Faura CC, Olaso MJ, Cabanes GC, Horga JF. Lack of morphine-6- glucuronide antinociception after morphine treatment. Is morphine-3-glucuronide involved? Pain 1996; 65: 25-30. [CrossRef]
21. Davies A. Cancer-related Breakthrough Pain second Edition Oxford University Press 2012.p.59. [CrossRef]

22. Życzkowska J, Wordliczek J. Subcutaneous and intravenous administration of analgesics in palliative medicine. Adv Pall Med 2009; 4: 153-60.

23. Aschenbrenner DS, Venable SJ. Drugs Treating Severe Pain, unite 6, chapter 23. Drug Therapy in Nursing, 3rd Edition. Philadelphia; Lippincott Williams \& Wilkins 2009; 373-98.

24. Gades NM, Danneman PJ, Wixson SK, Tolley EA. The magnitude and duration of the analgesic effect of morphine, butorphanol, and buprenorphine in rats and mice. Contemp Top Lab Anim Sci 2000; 39: 8-13.

25. Semple TJ, Upton RN, Macintyre PE, Runciman WB, Mather LE. Morphine blood concentrations in elderly postoperative patient following administration via an indwelling subcutaneous cannula. Anaesthesia 1997; 52: 318-23. [CrossRef]

26. Kirkpatrick T, Henderson PD, Nimmo WS. Plasma morphine concentrations after intramuscular injections into the deltoid or gluteal muscles. Anaesthesia 1988; 54: 293-5.

27. Rigg JRA, Braune RA, Davis C, Khadelwal JK, Goldsmith $\mathrm{CH}$. Variation in the disposition of morphine after IM administration in surgical patients. Br J Anesth 1978; 50: 1125-30. [CrossRef]

28. McDonald P, Graham P, Clayton M, Buhagiar A, Stuart-Harris R. Regular subcutaneous bolus morphine via an indwelling cannula for pain from advanced cancer. Palliat. Med 1991; 5: 323-9. [CrossRef]

29. Choinière $M$, Rittenhouse BE, Perreault $S$, Chartrand D, Rousseau P, Smith B, et al. Efficacy and costs of patient-controlled analgesia versus regularly administered intramuscular opioid therapy. Anesthesiology 1998; 89: 1377-88. [CrossRef] 